\title{
Disposable bag for thoracic drainage
}

\author{
O L E S E C HER
}

From the Department of Anaesthesia, Rigshospitalet (University Hospital), Copenhagen, Denmark

The use of thoracic drains in connexion with water seals often causes difficulties, even in departments where these are used daily.

The difficulties are (1) the cleaning of the bottles; (2) the fixing of the bottles to beds on which patients have to be moved; (3) that bottles break easily; and (4) that they take up too much space.

In the University Hospital (Rigshospitalet) we have adopted a simple method. Instead of bottles, disposable bags ${ }^{1}$ are used (Fig.1). The capacity of the bag is about $1 \frac{1}{2}$ litres. It is filled with water to a level marked $500 \mathrm{ml}$., hangs on the bed by a metal hanger like the urine bags in general use, and is connected to the drain.

At the top the bag has two pipe stubs of plastic. One is prolonged by a plastic tube reaching the bottom of the bag. This tube is fixed throughout its length to the inner side of the bag. The plastic tube, therefore, is always under the surface of the water, even when the bag sways widely.

1 The bag has been produced by Arbo-Bähr, Copenhagen

FIG. 1. Shows the practical use of the bag. The patient has had a cardiac operation and both pleurae have been opened. For this reason several drains are in use.

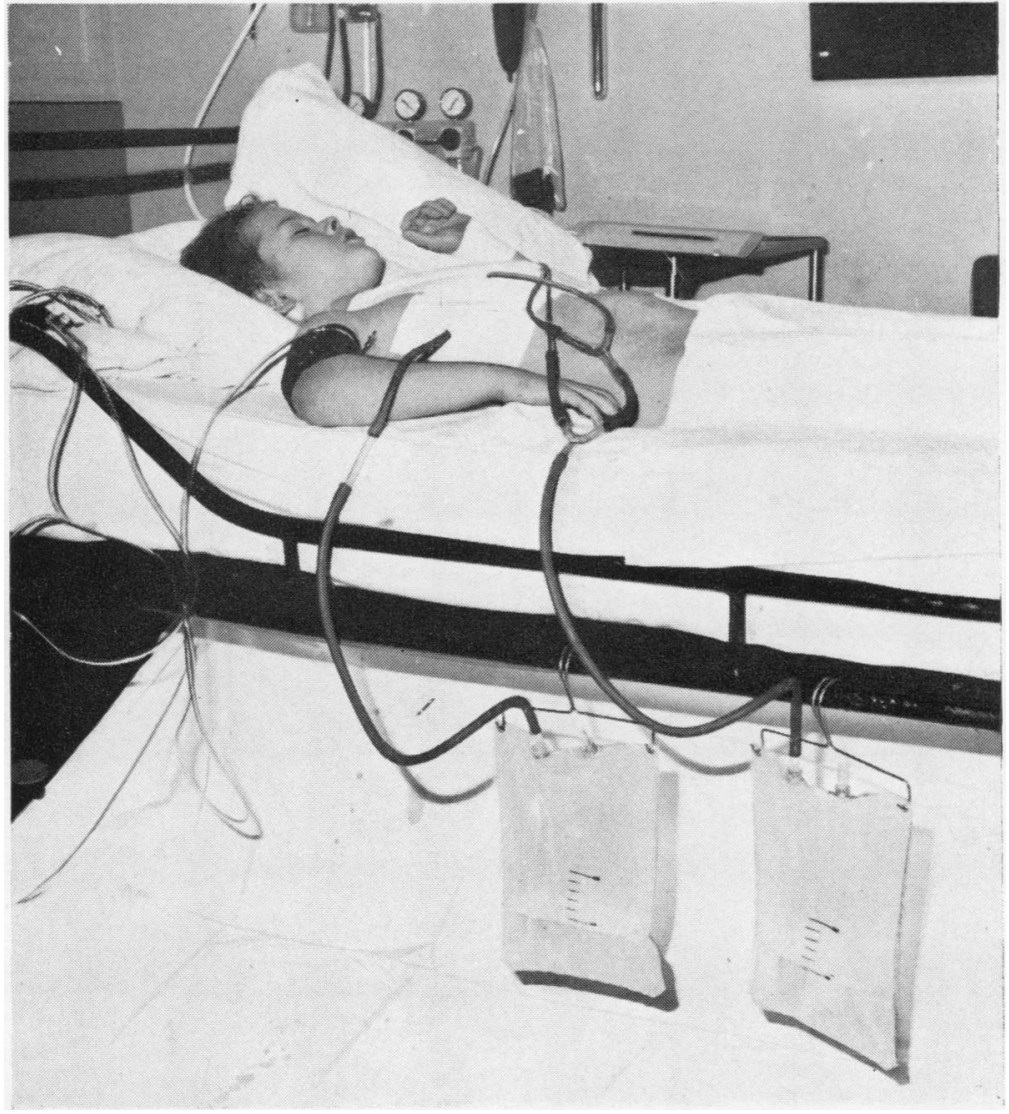




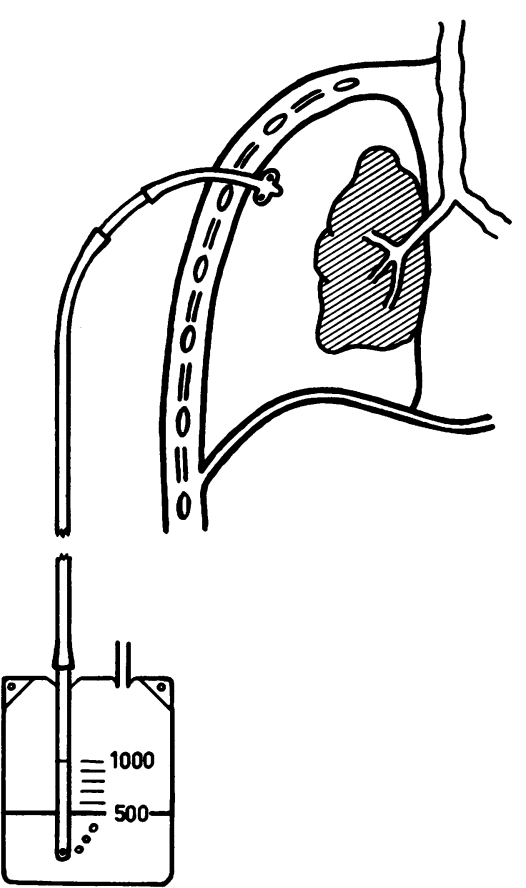

FIG. 2. A schematic drawing of the bag connected to the thoracic drain.

The other connecting piece ensures the passage of air in and out of the bag.
From the level marked $500 \mathrm{ml}$. and up to $1,000 \mathrm{ml}$. there are lines, each one indicating $100 \mathrm{ml}$., so that it is possible to read approximately the volume of the $\frac{\omega}{D}$ products from the thoracic spaces being drained.

The bag has the advantages that it takes up little space, it is disposed of after use, it is easy to hang on the bed, and it is always ready for use.

The bag affords the same benefits as a bottle, apart $\vec{\omega}$ from the fact that it is not possible to use it when a 9 constant vacuum is required for its walls are not $\vec{x}$ rigid.

The bag is produced in a sterile pack ready for $\omega$ use. Before use it is filled with $500 \mathrm{ml}$. of sterile water by means of a sterile funnel. Out of nearly $100 \vec{\omega}$ bags used, there has been only one in which the을 welding between the stub and the plastic tube leading to the bottom of the bag was not strong enough. The tube slipped out and air entered the pleural space. It is important that this should not happen; 3 each bag must be examined before use. If the bag is defective, the drain is clamped until a new bag is connected to the catheter. If a large volume of air $\vec{G}$ has passed into the pleural space, it may be removed $\omega$ by careful aspiration through the drain.

The bag must always be lower than the thorax, to prevent water running into the pleural space (Fig. 2).

Hospitals which do not use daily thoracic drains may have some plastic bags available, so that they $\stackrel{\mathbb{Q}}{\Omega}$ have the apparatus ready for a thoracic drainage. $\overrightarrow{\vec{P}}$ Departments in which drainage is used daily are $\frac{3}{3}$ saved much trouble. 